\title{
ENTIDAD PSICOSOMÁTICA, MOIRA E IDEAL: EL SÍ MISMO EN ILÍADA 18-22
}

\section{SEBASTIÁN VÁSQUEZ YEL \\ UNIVERSIDAD DE BUENOS AIRES. Argentina}

Resumen: En este escrito se desarrolla una crítica a las teorías que fundan su concepción del sí mismo del hombre homérico en la entidad psicosomática. Luego se elabora la comprensión que este hombre singular tuvo de su mismidad en relación a los límites de su existencia determinados como Moira y a la moral político-heroica que surge sobre estos límites.

Palabras clave: Mismidad Singular, Sí Mismo, Entidad Psicosomática, Moira, Ideal Heroico.

\section{PSYCHOSOMATIC ENTITY, MOIRA AND IDEAL: THE SELF IN ILIAD 18-22}

\begin{abstract}
In this paper a critique is developed to the theories that found their conception of the self of the Homeric man in the psychosomatic entity. Then it is develops the understanding that the singular man had of its own self in relation to the limits of its existence determined as Moira and to the politic-heroic moral that arises on these limits.
\end{abstract}

Keywords: Singular Selfhood, Self, Psychosomatic Entity, Moira, Heroic Ideal.

Recibido: 11.05.2016 - Aceptado: 12.07.2016

\section{Correspondencia: Sebastián Vásquez Yel}

Email: nainyel@gmail.com

Licenciado en Filosofía, Universidad de Chile.

Estudiante del Magíster en Estudios Clásicos, Universidad de Buenos Aires.

Andrés Lamas 822, Buenos Aires, Argentina. Cel. +54-9-11-25604086. 


\section{Introducción}

TC as teorías de la "subjetividad" homérica que fundan la elaboración del sí mismo del hombre homérico en la constitución psicofísica de sus entidades mentales, son investigaciones útiles, pero insuficientes para lograr una exposición de la mismidad singular ${ }^{1}$ que se encierra en dicha "subjetividad". Aquellas investigaciones determinan un momento de ésta, estableciendo la parte psicosomática como la definición del todo - lo que equivale a establecer un self abstracto e incompleto-, dejando de lado el que este todo se vive a sí mismo temporalmente. Por lo mismo, propongo la idea de que la existencia singular del hombre homérico se logra aclarar por medio del análisis de la Moira como destino, pero sobre todo como porción temporal en la que el hombre homérico se experimenta existiendo a sí mismo.

\section{Critica al enfoque sólo psico-físico de la mismidad singular}

Intentar determinar lo propio de un existente singular en la épica homérica a partir de un momento de su singularidad, v. gr., de uno de sus órganos o facultades, puede ser tan ingenuo como emprender la tarea de determinar a ese hombre a partir de una suerte de Geistesgeschichte. Heidegger (2005), al aclarar el propósito de su analítica existencial o su ontología del hombre, afirma que Descartes pone un punto de partida a la investigación filosófica de la "modernidad" con el descubrimiento del cogito sum. Si bien, Descartes investigó la naturaleza del cogitare del ego, él deja "enteramente sin dilucidar el sum, aun cuando éste haya sido tan originariamente establecido como el cogito" (p.79). El proyecto heideggeriano investiga este sum que no es simplemente el del cogito, sino, y sobre todo, el del ego, de la existencia singular que "cada vez soy yo mismo", a la que él llama Dasein.

Más allá de la analítica heideggeriana, es necesario plantearse lo siguiente: si en Descartes investigar el cogito equivalió a dejar de lado la forma del ser y singularidad del ego, ¿no incurrimos nosotros en el mismo error cuando fundamos nuestro análisis de lo propio de la existencia singular homérica en aquello que en Iliada es la $\psi v \chi \eta ́$, el $\theta v \mu$ ó o el vóos, y lo mismo

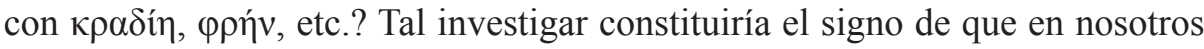
el pensamiento que va de Platón a la filosofía de la "modernidad" aún opera profundamente, y más radicalmente donde menos percibamos su influencia.

$1 \quad$ Según rae mismidad es: "1. f. Fil Condición de ser uno mismo. 2. f. Fil Aquello por lo cual se es uno mismo. 3. f. Fil. Identidad personal". Empleo el "singular" para resaltar la naturaleza particular o especial de esta mismidad, con el sentido de mismidad que es propia o perteneciente a "una" existencia humana. 
Concluir que thumós o nóos constituyen la mismidad y definición del hombre homérico es tanto como decir que la "racionalidad corpórea es la esencia del hombre" o tanto como que su "pasión encarnada es su definición". Pero también equivale a reificar al hombre, pues él ya no es más uno con su historia, sus vivencias, con él mismo y su carácter, esencialmente enlazado a su comunidad y a su ideal, sino que se lo desgaja de toda la multiplicidad y contradicción que se encierra en él, pasando a ser una "mera" subjetividad en tanto "sistema psíquico cardiovascular y pulmonar".

Esa idea, según la cual una parte del hombre define su integridad, la hallamos en Platón, en Fedón 115c, dónde, según Sorabji (2008), Sócrates es representado aguardando la muerte y "brindando a sus amigos tranquilidad: yo no soy mi cuerpo, sino mi alma racional" (p.17), creando la escisión entre dos planos diametralmente otros: por un lado, una psyché inmaterial, capaz de mirar racionalmente lo eterno e inmutable, asemejándose a aquello; y, por otro lado, un cuerpo devorado irremediable y constantemente por el devenir, resaltando con esto sólo un aspecto de aquello señalado con la palabra avi destacando un valor de self que no lo estará en una sentencia distinta.

En la épica homérica, precisamente, la pyché no demarca lo propio del singular vivo, ella es sólo un عið $\omega \lambda$ ov, una sombra o imagen, una copia del verdadero hombre una vez expirada. Rohde (1894) ya hacía ver que el alma, al morir el singular existente, "carece de conciencia propia, han huido de ella el espíritu y sus órganos; todas las potencias de la voluntad, de la sensibilidad, del pensamiento, han desaparecido al desintegrarse el hombre en los elementos que lo forman" (p.9) y pareciera que el cuerpo es visto como el "él mismo" (p.10) de los difuntos, contraponiéndose a la psyché $e^{2}$ Pese a lo anacrónico de afirmar que el hombre homérico es poseedor de un espíritu o voluntad-como Vernant (1987) hace ver de la voluntad y tal vez toda la crítica dirigida hacía Snell respecto de la idea de espíritu—, se puede observar que gran parte del pensamiento posterior respecto de la existencia singular homérica, parece estar

2 Rohde (1894) pensaba la existencia de un culto al alma operando como vestigio de épocas remotas en la épica de los poetas homéricos, cosa que Burkert (1977) refuta a partir de datos arqueológicos. El culto visto por Rohde implicaría que, para los griegos dispersos a lo largo y ancho de la Hélade, la psyché no es ni homogénea ni impotente - así la cremación del cadáver puede indicar un vestigio de lo que los hombres pre homéricos concebían como una agencia efectiva, por parte del difunto, en la realidad inmediata de los vivos, de ahí la cremación como forma de separar definitivamente el alma del mundo de los vivos. Sin embargo, para Rohde, la "acción caótica de los espectros" (p.31) no podía perdurar junto a "la fe en que el mundo es un cosmos, una organización armónica" como la poetizada por Homero (p.31). 
de acuerdo en el núcleo de la afirmación de Rohde.

Por tanto, lo propio del hombre homérico no es su psyché, ella sólo es una copia insustancial. De esta opinión es Snell (1965), que dice que Homero sólo sabe que la psyché anda errante por el Hades luego de abandonar el cuerpo, de hecho, Homero sólo la nombra en pasajes que se relacionan con la muerte o con el peligro de ésta y cuando habla de un aliento vital en el hombre vivo

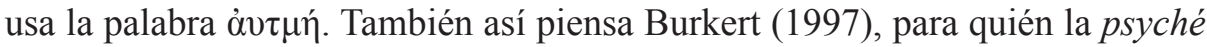
homérica no es la persona, no es portadora de sentimientos y pensamientos, no

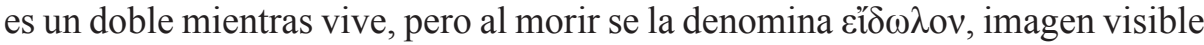
e impalpable. Para Sullivan (1994), es sólo después de Homero que psiché se va interpretando como asiento de funciones psicológicas y antes (1988) dijo que psyché asume este relieve en el tiempo de Platón. Sin embargo, para Sullivan la carencia de una palabra que enuncie algo parecido a lo que nosotros comprendemos como alma o mente no debe ser "tomado como evidencia de que se carecía del concepto de un alma unificada o self” (p.2). Clark (1999) afirma que no hay evidencia alguna que nos haga suponer que psyché sea el substrato de la vida mental consciente; a psyché se la identifica con el aliento exhalado en el momento de la muerte. Long (2015) señala que el destino de las psychaí, al morir el hombre, es el punto en que Homero más se diferencia de Platón. Para éste último la psyché no es "sólo la esencia de la persona viva, es también algo tan distinto del cuerpo que puede ser juzgado, recompensado, castigado, y renacido en [otro] cuerpo" (p.31), mientras que en Homero ella forma un "todo psicosomático" [psychosomatic wholes] (p.6) con otras entidades de naturaleza anímico-corporal y en el Hades no es más que una sombra.

Lo anterior es sólo respecto de la psyché, no de los demás órganos o entidades psíquicas y en este terreno sí hay controversia. Ésta consiste en la falta de acuerdo acerca de la unidad que el hombre homérico constituía con sus entidades psíquicas, es decir, si el hombre homérico se experimentaba a sí mismo como uno con sus órganos mentales o desgarrado de ellos.

Esta última tesis es defendida por Sullivan (1988). Según este autor, el hombre homérico no lograría hallar la síntesis entre él mismo y sus entidades psíquicas, las que son "facultades indeterminadamente corporales" (p.9), con lo que se indica el aspecto físico que estos términos poseen y el grado en que lo hacen. Tal como antes defendiera Snell ${ }^{3}$, se trata de un hombre fraccionado. Sin

3 Snell (1965) deriva lo fragmentario del hombre homérico como entidad mental de una concepción fragmentaria de la mirada y del cuerpo. Decir que thumós, nóos y psyché son partes del alma equivale a pensar el alma como un todo, cosa que no pasó en Homero. En él, aquellos órganos corporales, tienen sus propias funciones: thumós, 
embargo, según Sullivan (1994), en Homero nos encontramos con una noción de persona o "self", mas no con un concepto claramente determinado. Él dice:

La "persona", por tanto, emerge claramente en la poesía Griega temprana. Esta "persona" se relaciona con todas las entidades psíquicas en su interior, pero sin llegar a identificarse totalmente con ninguna (p.104).

Luego de estudiar las seis entidades psíquicas que aparecen en el Zeus de la poesía homérica - a saber: nóos, phrén, thumós, êtor, kêr y kradiê-, Sullivan concluye la veracidad de esta escisión entre las facultades u órganos psíquicos de Zeus y su mismidad singular. Sin embargo, Zeus sabe quién es él: "Así sabrán en qué medida soy el más poderoso de todos los dioses"4 (Il.8.17) es la amenaza que contrapone con su ser al de los demás dioses.

Clark (1999), por otro lado, es contrario a esta idea y bien se define su concepción del hombre homérico por la conceptualización de un "todo psicosomático" que Long (2015) hará posteriormente inspirado en su trabajo.

Clark (1999) afirma que las entidades psíquicas en Homero son "manifestaciones en acción de un todo humano indivisible, un todo donde la complejidad de la vida mental hace mejor sentido si la aprehendemos sin tratar de dividir al hombre en mente y cuerpo" (p.61). Así se concluye, de esta definición, que en Homero "no se opone la vida mental a la vida del cuerpo, sino que se las toma como un todo indiferenciado" (p.115). Esta afirmación se hace en un apartado que se titula The body and the self are one (p.115). La lógica que trabaja en la idea de Clark es que la singularidad de la persona es la misma cosa que su mente. Teniendo esta identidad como base, es que luego se establece la identidad de vida mental y cuerpo, lo que da como resultado la identidad final de self y cuerpo mencionada en el título ya citado. De esto se deduce que mente, cuerpo y aviós son intercambiables en Homero.

Pero ¿es adecuado pensar la mismidad del hombre en Homero - y no sólo en él, sino también en general-identificándola con la mente? Más allá de que en Homero la mente sea una cuestión corporal, fisiológica, más allá de que la mente sea un sistema cardiovascular y pulmonar, ¿no es radicalmente platónico e incluso propio a la filosofía de la "modernidad" el planteo según el cual la singularidad esencial, lo que le da definición y sentido a una existencia

\footnotetext{
órgano anímico espiritual, sobre todo emocional, principio del movimiento, y nóos, órgano intelectual, encargado de las impresiones.

Sigo la traducción de E. Crespo (2015).
} 
es justamente su vida mental? De acá a operar bajo la lógica de la conciencia de Hegel, en tanto sí mismo del hombre, no hay tanta distancia, con la diferencia de que "el aspecto más importante y también el más novel de la mirada de Hegel es el énfasis hecho en el aspecto social de la realidad" (Martin, R. y Barresis, J., 2006, p.188), un énfasis que se manifiesta en su insistente afirmación de que "un embrión carente de relaciones sociales no es aún humano" (p.188), siendo una de las formas de conciencia más pobre.

El tipo de investigación de Clark o de Long busca la consistencia del ego a partir de estos sistemas de órganos psíquicos. Definen el todo de la existencia humana a partir de una parte que vendría a ser el "todo psicosomático". Yo digo que esto es tan cartesiano como decir "yo soy una cosa que piensa" — llénese ese "pienso" con afectos, imaginación, lógica, y esa "cosa" con músculos, tendones, viseras, nervios, lo que se quiera. En lugar de esto, prefiero plantear que esta entidad física pasa a constituir una mismidad singular y existente cuando se interrelaciona con una comunidad y consigo mismo en relación a una moral, y esto en el intertanto de la porción o Moira que se consuma con su muerte.

El órgano psíquico es solo un una mismidad abstracta, no aún una existencia singular concreta. Estos análisis equivalen a detener la existencia del hombre en un periodo particular, diseccionándolo y constatando que en él la mente opera bajo el aspecto de ciertas entidades físicas. Sin embargo, esto no deja de ser útil, pues "para pensar el ser de algo [...] los griegos de la época arcaica no tienen más remedio que expresarlo sirviéndose del vocabulario de lo corporal" (Vernant, 2001, p.39). De hecho, se puede afirmar que para el griego ciertamente había una cierta conciencia de sí que hace alusión a la dimensión de lo corporal. Las palabras de los órganos psicosomáticos establecen un código que les permitía a los hombres "expresar o pensar sus relaciones consigo mismos, el modo de presentarse a sí mismos de manera más o menos clara, más o menos unificada o dispersa" (p.18).

Pero, a la vez, la naturaleza de estos análisis resulta insuficiente para definir lo que es lo singular y propio del ser humano, aparte de lo ya señalado, por dos razones más. Primero, lo que determina la relación del hombre homérico con los otros no está constituido únicamente por sus órganos mentales, sino que el rostro, la cabeza, la estatura, la belleza o fealdad, la juventud o vejez son lo que determina en parte al hombre como un singular ante el otro (p.18), como se puede observar por la forma en que Aquiles se refiere a Patroclo; cuando va a vengarlo asesinando a Héctor él dice: “Ahora iré en busca del matador de esa querida cabeza para mí” (Il.18.114). Además de esto, según Vernant, se podría establecer una comprensión de sí por medio de la comparación de la 
superabundancia del cuerpo de las deidades y la terrenal fugacidad del cuerpo mortal, es decir, se alcanza un "sistema simbólico codificador de las relaciones consigo mismos, con el otro y con lo divino" (p.19) por medio del estudio del cuerpo. Semejante sistema no se contenta con la idea de que el cuerpo como mente constituye su totalidad; precisamente la idea de un sistema es que éste siempre es una totalidad que aúna dentro de sí momentos, sin contentarse con la mera parte.

Por lo demás, Vernant se plantea la tarea de ocuparse de individuos fuera de lo común, uno de los cuales es el héroe guerrero. Para lograr lo heroico - distinción máxima en el mundo homérico y la diferenciación radical respecto de las cabezas anónimas de los guerreros ordinarios-, el "héroe no puede contar con su cuerpo ni con ninguna otra cosa que tenga relación con él" (p.31). El guerrero, para hacer de su singularidad una heroica, ha de buscarla muerte en la flor de la juventud, belleza y virilidad, en el furor de la guerra. Con esto su singularidad se cincela perpetuamente en el corazón de la vida comunal. A su vez, para afirmar tan radicalmente su mismidad, al héroe le toca "aislarse, incluso llegando al enfrentamiento con el grupo constituido por los suyos, arrancarse de ese conjunto formado por sus iguales y sus jefes" (p.209), es decir, debe adoptar una actitud moral, política.

Una última cosa es ver cuál es la constitución psicofísica que opera en la existencia del hombre homérico. En ella hay que definir dos cuestiones principales. La primera es decidirnos por una de las antítesis representadas por Sullivan y Clark respecto de la unidad que guardan aquellas entidades con la mismidad del hombre homérico. La segunda es ver si sus entidades psíquicas son órganos o abstracciones de sus funciones.

Respecto de la primera, tal vez sea mejor dar un término medio entre Clark y Sullivan. De lo anterior, se desprende que no podemos quedarnos con la idea de Clark según la cual la identidad de vida mental y corporal es la mismidad del hombre homérico. Sin embargo, esto no niega la definición de un "psycho somatic wholes", siempre que se vea que este todo psicosomático no constituye la enérgeia de la persona homérica, sino sólo su potencia. Las entidades psíquicas y los órganos cardiovasculares forman un sistema psíquicocorporal, un todo psicosomático, sin llegar a ser éste la definición total de la mismidad singular en Homero.

La segunda cuestión puede ser útil para aclarar la primera, en el sentido de ver cómo es que los órganos se muestran tanto como entidades corporales como también mentales. Al analizar tres pasajes de Ilíada 20 se evidencia lo anterior claramente. El primer pasaje está en el verso 403, donde se cuenta 
como muere Hipodamante. Cuando éste comienza su huida, Aquiles lo asesina hiriéndolo por la espada, entonces Homero dice: "Exhaló la vida con un bramido"

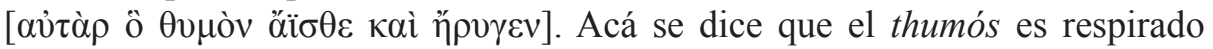

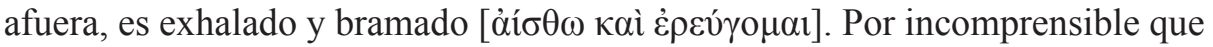
suena la idea de "respirar fura" un órgano, pareciera como si thumós hubiera sido identificado con psyché. De esa identificación thumós aparece como una suerte de órgano sustentador o portador de vida.

Por otro lado, luego de ver a su hermano Polidoro morir con las vísceras

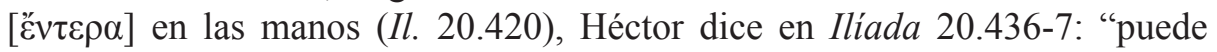

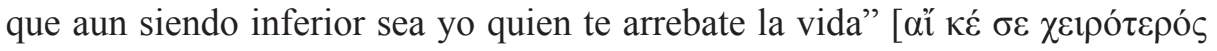

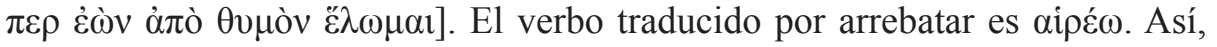

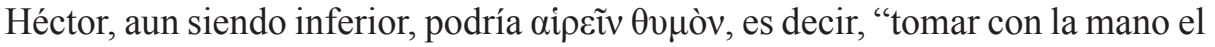
thumós" ${ }^{\circ}$ de Aquiles, aunque acá tal arrebatar se realizaría arrojando una lanza

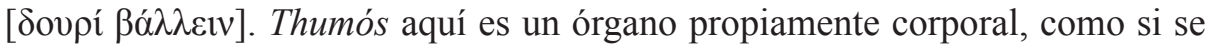
amenazara con arrancar del pecho el corazón.

Un poco antes, Aquiles, al ver a Héctor aproximarse, dijo: "Ya está cerca el hombre que más me ha fustigado el ánimo, el autor del asesinato de

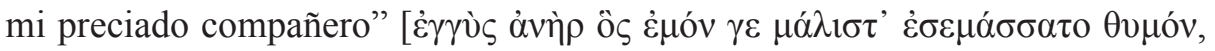

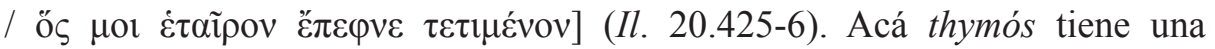
función propiamente subjetiva, Héctor ha $\dot{\varepsilon} \sigma \varepsilon \mu \alpha ́ \sigma \sigma \alpha \tau o \theta v \mu o ́ v$, él ha "afectado grandemente" o "tocado en lo más vivo al thumós" de Aquiles al asesinar a Patroclo, casi como una suerte de dolor psicológico localizado en el pecho.

De estos tres pasajes se desprenden tres naturalezas diversas propias de thumós. Primeramente thumós aparece como una suerte de psyché, como una entidad corporal que puede ser "respirada fuera" al momento de la muerte, mostrándose como vida, como entidad que con su presencia diferencia lo vivo de lo muerto. Luego thumós se muestra como una entidad totalmente corporal, una que puede ser tomada del pecho con la mano o una lanza. Finalmente como órgano psíquico propiamente, encerrando, por medio de la vida y del estar vivo, la síntesis de lo mental y lo físico.

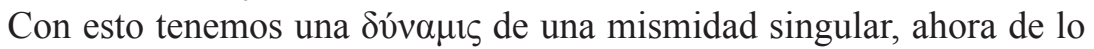
que se trata es ver cómo existe, cómo acontece, cómo se hace concreto este poder ser. Sin embargo, se tiene que preguntar hasta qué punto el "estar vivo del organismo completo" es lo que dota de unidad o mismidad a estos momentos físicos y psicológicos, pues entonces sería la mismidad singular en cuanto existencia lo que permitiría tal unidad y no otra cosa.

$5 \quad$ La primera entrada de aipś

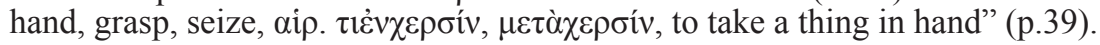




\section{Moira, ideal heroico y mismidad}

Un misterio que podría mirarnos fijamente es el de dar respuesta a la pregunta por lo propio del ser humano en general y todavía más en Homero. Más allá de plantear una mirada esencialista, la que bien podría tomar la forma de la pregunta clásica y metafísica acerca de "qué es en general"6 lo humano, aún más misterioso es preguntar ¿quién es él?, ¿qué define $s u$ singularidad?7 Un enigma incluso "fatal", hasta para un sabio. Pero esta fatalidad exige ser contestada por medio de ella misma, tal como los grandes griegos de Homero lo hicieron al superar su propia fatalidad, afrontándola, buscándola.

Aquella singularidad tuvo una certeza acerca de sí: la fatalidad misma que le fue dada, la muerte que recae como $\tau \dot{\varepsilon} \lambda$ os, como frontera inquebrantable de su existencia. En griego esa fatalidad se decía $\pi$ ó $\mu$ os, palabra que, según Chantraine (1968), proviene de $\pi i ́ \pi \tau \varepsilon v$ "caer, abatirse, echarse a bajo" (p.905); de allí que $\pi$ ó $\mu$ o sea "aquello que le cae a uno, destino" (p.906), ganando un sentido negativo cuando se vincula con $\theta \alpha \dot{v} \alpha \tau$ co $\mathrm{y}$ en Homero teniendo siempre el sentido de "destino infeliz", designando así la desgracia y de la muerte, pues muerte es el destino que sobre todos recae.

Otra forma de denominar a esa fatalidad es oĩ $0 \varsigma$, "destino"; v. gr., oíódıvos significa "el canto del destino", teniendo un valor negativo como se

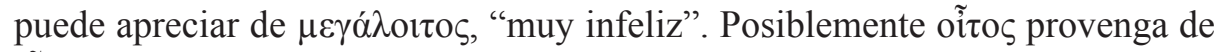
عĩul, "ir", apuntando a la idea de la marcha irrevocable que el hombre emprende hacia el término de su destino (Chantraine, 1968) o este término cómo lo que sobreviene/acontece a cada cual (Liu, 2010).

De estas palabras resulta fácil observar que el hombre homérico tenía una experiencia de su existencia claramente asumida como finita, totalmente consciente de lo efímero de su ser y se puede afirmar, con Jowsey (2011), que "mesura y destino son para los mortales su propia verdad última" (p.11). La conciencia incuestionable de la muerte resulta cosa obvia cuanto se recuerda que Ilíada es la reunión de los cantos que relatan los últimos días de una larga

6 Para Aristóteles la pregunta de la filosofía antigua interroga a "lo que es" respecto de sus determinaciones más universales, esta pregunta es "la cuestión que se está indagando desde antiguo y ahora y siempre, y que siempre resulta aporética, qué es lo que es" (Met. 1028. b.5).

$7 \quad$ Para Heidegger la pregunta “¿qué es?” da cuenta de la naturaleza de todo ente que no sea el Dasein o el hombre; la pregunta acerca del hombre sería entonces: “¿quién es el Dasein?”. 
guerra de ya casi diez años. Sin embargo, $\theta \alpha ́ v \alpha \tau o \zeta$, como el $\tau \varepsilon ́ \lambda o \varsigma$ inexpugnable, no es la única certeza que el hombre homérico tiene respecto de su mismidad. Para él, la existencia es eso que experimenta como propio, comenzando por el día en que nace y terminando por aquel otro en que muere; ésta es su porción,

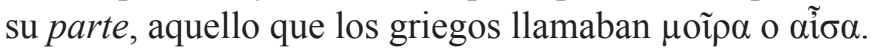

La palabra $\mu$ oĩ $\alpha$ viene de $\mu \varepsilon i ́ p o \mu \alpha$ (Chantraine, 1968), "recibir una parte", así $\alpha \pi$ о $\varepsilon_{i} \rho \mu_{\alpha 1,}$ v. gr., es "tomar una parte", un com-partir. "Tener su

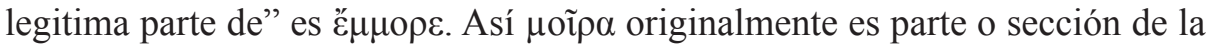

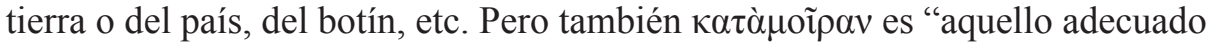
o conveniente", у ноĩ $\alpha$ es también "destino" y por lo mismo "muerte". En Homero la idea de destino se define en parte por su inevitabilidad, pues "como es sugerido por $\mu$ oĩ $\alpha$ y $\alpha \tilde{\sigma} \sigma \alpha$ : cada uno tiene una parte de fortuna, una porción viniendo a todos los humanos" (Liu, 2010: 22).

$\mathrm{Si}$ oĩtoৎ significa destino o fatalidad por su relación con eĩu1, es decir, porque en ella se remarca lo inevitable del ir hacia la muerte, y $\pi$ ó $\tau \mu$ o $\varsigma$ significa destino, remarcándose que es la muerte lo que sobre todos recae, y relacionamos estos términos con $\mu$ oĩ $\alpha$, en tanto la porción delimitada en que se da la existencia de cada uno, entonces podremos representarnos lo que ella pudo haber significado para un hombre homérico. La $\mu$ oĩp $\alpha$ es lo que le adviene a uno $\mathrm{y}$, en tanto adviene como nacimiento y muerte, es lo que determina los límites concretos y temporales en que uno ha de acontecer, es la demarcación a la cual el ser humano ha sido entregado el día en que se le da el ser, es lo único por lo cual el hombre está entregado a un existir temporal, vuelto hacia la muerte y de manera más o menos clara para sí mismo.

La idea del estar entregado a la propia existencia, o mejor dicho, la idea del haber sido dado por la $\mu$ oĩpa a la muerte como condición primordial de la existencia singular se puede apreciar cuando Zeus, lamentándose, pide a los dioses reflexionar acerca de la inminente muerte de Héctor a manos de Aquiles (Il.22.168-76), a lo que Atenea dice:

¡Padre del blanco rayo y de la negra nube! ¡Qué has dicho! ¿A un hombre mortal y desde hace tiempo abocado a su sino pretendes sustraer de la entristecedora muerte?

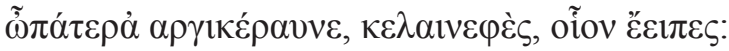

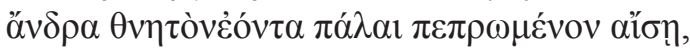

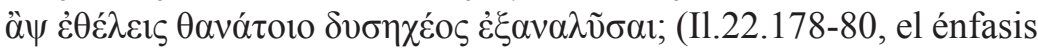
es mío). 
La palabra griega acá traducida por "abocado" es $\pi \varepsilon \pi \rho \omega \mu \varepsilon ́ v o v$, "determinado por el destino" cuando va acompañada por el dativo de Aisa. Esta palabra es un participio pasivo, de un verbo de dar, entregar o suministrar: $\pi$ que Héctor esté "predeterminado por el destino" es la de "haber sido entregado o dado" hace mucho ya por Aisa. El reclamo de Atenea podría ir más allá de su clara enemistad a los troyanos, pues liberar a Héctor de la "estrepitosa muerte" supone la negación de su condición mortal destinada o proporcionada. Héctor debe morir, es lo que Aisa tejió para su existencia el día mismo en que nació y precisamente por haber nacido, por existir, es que tiene que morir. Ante esto ni siquiera Zeus, el Padre Olímpico que siente su corazón lamentarse por Héctor, puede hacer algo, pues liberar al hombre de los límites que definen el contorno de su propia existencia, equivale a desproporcionarlo, a hacerlo acontecer vं $\dot{\varepsilon} \rho \mu$ ĩ $\rho \alpha$, es decir, ponerlo por encima y fuera de lo destinado, de la porción otorgada.

Según Vernant (2001), la muerte misma es el testimonio de la precariedad inherente al cuerpo humano, constituyendo su condición existencial, entretejiéndose en su vida como uno de los "polos opuestos de lo positivo y lo negativo, del ser y de su privación" (p.21). La muerte realza la condición finita del existir humano, siendo ella ese vestigio de "oscuridad y de no-ser que el mundo ha heredado desde su origen «caótico»" (p.21) y del cual el hombre jamás puede deshacerse. En el plano intermedio entre esta absoluta indistinción de la negra noche del caos y la muerte, y la total luminosidad de los dioses, acontece el existir humano. Y precisamente, por habitar tal plano, en donde sombra y luz posibilitan el ver mortal, es que la existencia del hombre llega a singularizarse hasta constituir un sí mismo.

Tomando esto, se explica que la muerte, como punto final puesto en la vida del hombre no es sólo como un capricho de alguna deidad que juguetea dentro del mundo arcaico, más bien, es como si el límite de la existencia humana fuera un momento necesario de la historia del cosmos que habita. Arrancar a Héctor de las fauces de la muerte es vi $\pi \hat{\varepsilon} \rho \mu o \tilde{\rho} \rho \alpha$ en este sentido, pues arrancarlo de los límites de su porción es también atentar contra la physis en él y contra aquella en la que él aparece.

Jowsey (2011) dice que la "porción asignada [allotted] a los mortales es su mortandad, mientras los dioses han sido asignados con inmortalidad. Esta es la distinción primaria entre mortales e inmortales: muerte" (p.10). Uno puede preguntar hasta qué punto los dioses tienen una porción, una moira "existencial", en el sentido de que la propia inmortalidad de la que son dueños los dioses los 
hace ilimitados en relación a la vida. Por lo mismo, la "existencia" de los dioses, al no estar sometida a la muerte, es más bien desmesurada, desproporcionada, pues ¿cómo ha de haber una mesura en lo ilimitadamente vivo? Allí todo límite, todo término y determinación se ha de perder, diluyéndose en el fulgor de los felices $\dot{\alpha} \theta \alpha ́ v \alpha \tau o r$.

Sin embargo, esta "existencia" divina, el modo de ser de los dioses, no está substraída y liberada de la muerte y la Moira. Jowsey, citando a Dietrich, dice que el destino "ha sido visto como "un poder absoluto al cual incluso los dioses" deben inclinarse" (p.12). Esto se ejemplifica con el pasaje de Ilíada ya citado (22.178-80), en que Atenea recrimina a Zeus la intención de salvar a Héctor de las manos de Aquiles. Allí decíamos que liberar a Héctor de la muerte sería vi $̇ \grave{\varepsilon} \rho$ oĩ $\rho \alpha$, y le dábamos a esto el sentido de sacarlo de su propia moira, lo que finalmente redundaría en una desfiguración de la mismidad existencial del héroe, desmesurándolo, desproporcionándolo.

Pero este poder ser $v \pi \dot{\varepsilon} \rho \mu o i ̃ \rho \alpha v$, la posibilidad de poder ser por encima o contrario a lo pro-porcionado o destinado, también se observa cuando los hombres, encontrándose en claro peligro de muerte, deben ser salvados por las deidades, aun estando ellas alineadas en el bando enemigo. Este es el caso de Eneas, héroe troyano que es salvado por Poseidón en Ilíada 20.318-29. Si Hera, percatándose de la posible muerte de Aquiles ante Eneas, primero insiste en tratar de auxiliar al Pelida, luego deja en libertad de acción a Poseidón, cuando éste afirma que el destino de Eneas es "eludir la muerte" [ $\mu$ ó $\rho \mu o v ~ \delta \varepsilon ́$ oó $\varepsilon \sigma \tau$ ' $\dot{\alpha} \lambda \dot{\varepsilon} \alpha \sigma \theta \alpha 1]$ (Il.20.302), impidiendo de esta manera que la semilla de Dárdano se extinga. La muerte de Eneas a manos de Aquiles sería vi $̇ \dot{\varepsilon} \rho \mu$ ĩ $\rho \alpha v$, como se observa de lo dicho por Poseidón al campeón troyano, esto es, que se guarde de luchar contra Aquiles "no sea que llegues antes de tu destino a la morada de

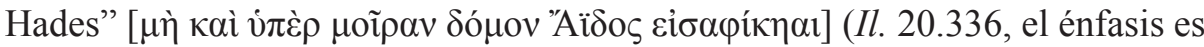
mío).

En este sentido es que los dioses sin muerte están expuestos a ella. No es la muerte "vivida" en carne propia, sino aquella irrevocable a la cual estas vidas ilimitadas están compelidas a agenciar casia a modo de causas secundarias, mostrándose ella, en palabras de Adkins (1960), "fuera del control de los dioses” (p.17). Más bien, estas vidas inmortales son las que están constreñidas a sostener la vida mortal hasta hacerla llegar a su télos, a no dejarlas caer en la lúgubre noche del caos antes del tiempo debido. Así es que la mismidad de los fuertes perfiles delineados por el canto homérico-al modo en como un vigoroso sol muestra la totalidad de un mundo remoto, poético y poetizado- es una existencia que en su ser está atravesada por fuerzas desmesuradas que la 
atan poderosamente a su destino y naturaleza, una existencia que tiene que ser tal como es, entregada a sus límites, incardinada en ellos como momentos del cosmos del que surgen.

Según Dietrich (1962), la idea de Moira como divinidad que hila el destino de un ser humano al momento de su nacimiento, no ha de "haber tenido un sonido extraño para una audiencia homérica, especialmente cuando la Moira misma en Grecia estaba conectada con el nacimiento" (p.100). Ella sería una suerte de divinidad de la naturaleza y el parto. Aunque difícil de comprobar, hay inscripciones en que Moira es relacionada con deidades asociadas al nacimiento. Así, en la creencia popular, la función de la Moira era marcar, durante los partos, el momento de la muerte del recién nacido.

Moira o Aisa, como deidad que hilando durante los partos determina el último día del héroe, aparece en dos pasajes en Ilíada ${ }^{8}$. El primero dice así:

Ya sufrirá más tarde todo lo que el hado tejió con su hilo para él al nacer, cuando su madre le dio a luz

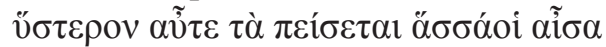

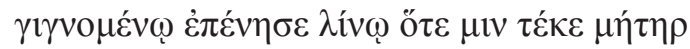
(Il.20.127-8, el énfasis es mío).

Esto lo dice Hera para incitar a los dioses a ayudar a Aquiles ante

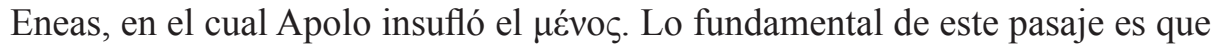

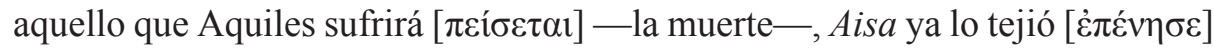
cuando su madre lo alumbraba. Sin embargo, esto hilado durante el primero de sus días, Aquiles aún no lo ha de padecer, no ahora, sino que ha de cumplirse "más tarde" [ü $\sigma \tau \varepsilon \rho \nu]$. Con esto se muestra la existencia del hombre homérico atravesada de principio a fin por la Moira o Aisa, y por la comprensión de sí que en éstas se fundamenta.

Como antes vimos, moira se empleaba para la repartición de porciones de tierra, botines; no obstante termina designando mucho más que el límite de los entes que no tienen el modo de ser de los hombres y mujeres. Moira termina por delimitar, definir o determinar el contorno de la existencia singular humana de un modo más o menos gráfico, realzando la naturaleza mortal de la condición humana, pero también enlazando a ella un aspecto vital, tener que morir, estar destinado a morir, es existir plenamente, es estar entregado radicalmente a la

$8 \quad$ Otro pasaje está en Odisea 7.196-9, pero acá sólo analizaremos el pasaje de Ilíada que se cita a continuación. El otro pasaje en Ilíada, que tampoco se analizará acá, es el de 24.209-10. 
propia existencia como lo proporcionado.

Esta definición aún es abstracta, tal como aquella que vio el sí mismo del hombre homérico en el órgano psicosomático. En este momento de la exposición de la mismidad homérica en que ahora nos encontramos, el hombre homérico ha dejado de ser un embrión; ahora existe y en su experiencia de sí muestra una comprensión de su naturaleza: hay en ella la certeza de la propia muerte. Sin embargo, el hombre homérico pose un orgullo exuberante ante esta muerte infinita y lúgubre a la cual es entregado su aliento una vez que aquel

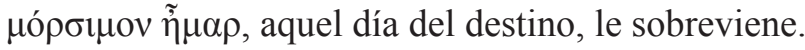

\section{II}

Los grandes griegos de Homero supieron superar la propia fatalidad afrontándola, buscándola. Detenernos en cómo Aquiles existiendo contesto a la negra muerte, a la poderosa Moira y en el fondo a su cosmos entero, es tal vez lo único que nos podrá mostrar al hombre homérico real.

Adkins (1960) señala que en la Moira no debemos ver más de lo que hay, pues the 'fates' are 'fates of death', not 'fates' in general (p.17). Si analizamos cuantitativamente las cosas que recaen dentro de la "porción" de un hombre, se pueden enumerar muy pocas. Adkins señala las siguientes: su muerte; la muerte a manos de otro; la seguridad de que algo pasará sin certeza de cuándo o cómo; y la promesa de que si hace algo, entonces otra cosa se sucederá. Ahora, retomando la definición anterior de moira como porción que marca los límites en los que acontece la existencia singular del hombre, y sirviéndonos de lo que Adkins señala, debemos afirmar que la moira no determina lo que el hombre haga consigo mismo dentro de dichos límites ni lo que él mismo llega a ser al consumar completamente la frontera delimitada. Más bien, el modo en cómo acontece el hombre homérico está vinculado a un ideal social, el que se erige fundado en la concepción finita que el hombre tiene de su existencia, ideal moral expresado por la "bella muerte".

La suprema afirmación de sí en el mundo homérico es la total negación del sí mismo, de la existencia encuadrada en los márgenes de la fatalidad, del cuerpo, de los emblemas que porta como símbolos distintivos, esto es: la muerte. Sin embargo, y de acuerdo a cómo ella sea, lo propio y mismo del hombre se resguarda como parte de la memoria de su comunidad, ganando así cierta inmortalidad. Es por medio de esta extraña dialéctica que, v. gr., Aquiles pasa a ser una singularidad totalmente diferenciada del resto de las anónimas cabezas de los guerreros que se disuelven, en tanto singularidad, en la oscuridad 
del Hades. Solamente través de la comprensión de la propia condición mortal y por la realización de la muerte como margen definitorio de la propia existencia es que ésta se eleva al plano de la mismidad de sí.

Desde que Aquiles se entera de la muerte de Patroclo hasta asesinar a

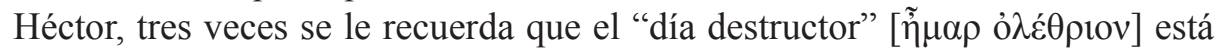
ya cerca ${ }^{9}$. Ante estas advertencias Aquiles siempre contesta con una certeza implacable. Janto le dice, justo antes de ingresar al campo de batalla, que él y Balio podrán correr tan rápido como el Zéfiro, sin embargo: "tu destino

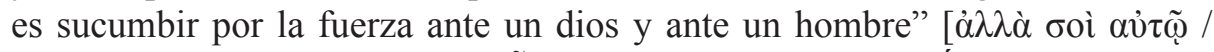

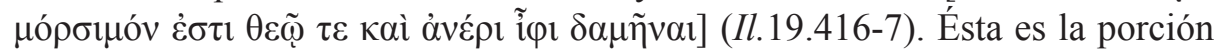

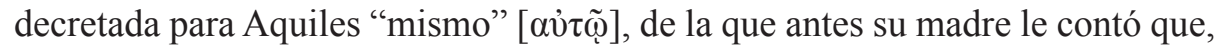

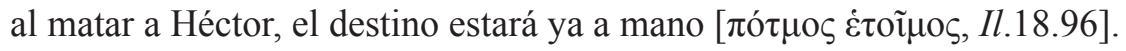

Luego de que Janto perdiera la voz humana por obra de las Erinias, Aquiles le contesta:

Bien sé también yo mismo que mi destino es perecer aquí, lejos de mi padre y de mi madre. Pero, a pesar de todo, no pienso parar hasta saciar a los troyanos de combate.

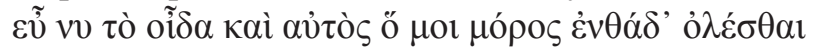

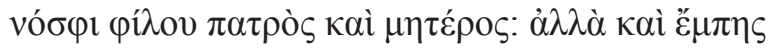

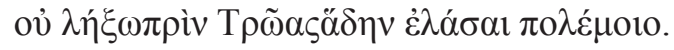
(Il.19.421-23, el énfasis es mío).

"Incluso ahora, bien sé yo mismo que acá mi destino/porción es la destrucción" podría ser una traducción del verso 421. Aquiles sabe claramente que lo que está por emprender sella la totalidad de su existencia, sabe, y ahora más que nunca, que la venganza heroica lo está incardinando intrincadamente hacia los límites de su existir, hacia la muerte, hacia la disolución de su propia psyché en la noche de la nada. Sin embargo, no se detendrá hasta saciar con pólemos a los troyanos.

Según Vernant (2001), la muerte es representada por Gorgo y sus hermanas. Si la visión de estas monstruosidades es insostenible, es pues en sus rostros se mezcla "lo humano, lo animal y lo mineral, [ellas] conforman la figura del caos, del retorno a lo informe, a lo indistinto, a la confusión de la Noche primordial" (p.117). Estas deidades ctónicas simbolizan la muerte como una perdida completa del sí mismo; así, el rostro de la muerte es el de una nada 
infinita, en donde no es posible distinguir [se] algo respecto de otro, pues no hay límite alguno y, por tanto, la existencia, en tanto proporción en la cual se encierra el ser del mortal, no tiene parte alguna. Esta conciencia la expone Aquiles y es uno de los elementos conformantes del ideal heroico. El otro elemento es lo que hará de sí con esta certeza, pues "la muerte temprana, cuando es asumida, posee su contrapartida: la gloria inmortal, la gloria celebrada por las gestas heroicas" (p.53).

Cuando Aquiles ingresa a la batalla para vengar a Patroclo, tiene la certeza de esta muerte desmesurada en la mirada. Sin embargo, y en esto va su heroicidad, él no deja de adentrarse en el fragor guerrero. Antes Aquiles decía a su madre que su $\theta v \mu$ ós, por un lado, le ordena no vivir hasta matar a Héctor (Il.18.88-93) y, por otro, le es necesario dominarlo en tanto entidad sobrepasada por los afectos que surgen de la noticia de la muerte de Patroclo, apreciado

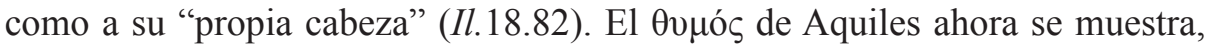
no al modo de una lámina medica en la cual se aclara alguna de sus funciones, sino como carne de su existencia palpitante y excedida de dolor e ira; es carne

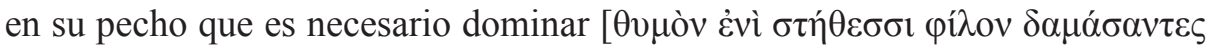

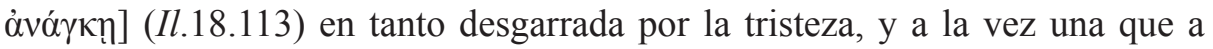
él mismo domina y con ira lo lleva a la batalla, y justamente a precio de su propia vida; un acto repartido en donde le toca ser gobernado por y a la vez ser gobernante de aquello que lo arroja al combate.

Luego de esta conversación dice a su madre:

Ahora iré en busca del matador de esa querida cabeza para mí, en busca de Héctor. Mi parca yo la acogeré gustoso cuando Zeus quiera traérmela y también los demás dioses inmortales.

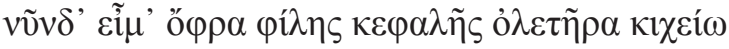

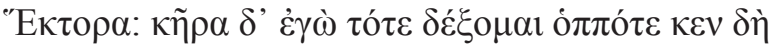

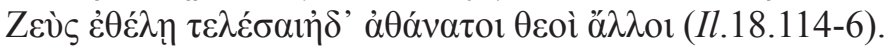

Aquel que hará de sí mismo la carne existencial del ideal heroico no se queda como petrificado mirando en los ojos de la certeza de la muerte, más bien, se adentra cada vez más en esta consecuencia, haciéndola real en él mismo. "La parca, ahora y entonces, yo la aceptaré cuando venga" (Il.18.115) es lo que Aquiles dice para luego recordar a Heracles, quien, "aunque fue el mortal

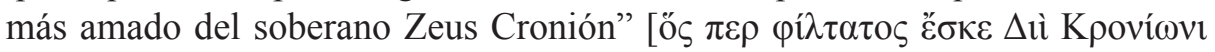

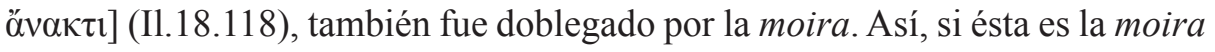

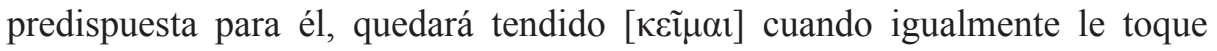


morir (Il.18.121). Sin embargo, Aquiles dice algo aclarador de lo que busca con este duelo con el destino y la muerte: "Mas ahora aspiro a ganar noble gloría"

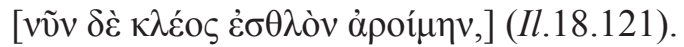

Habiendo muerto Patroclo, esa cabeza estimada como la existencia, y teniendo a la vista que matar a Héctor es sellar su propio sí mismo, ya para Aquiles la ofensa de Agamenón o la muchacha prenda de honor, o las muchas recompensas que le son ofrecidas para conciliarse con el más rey de todos le son cuestiones vacuas. Allá él, en sus manos quede procurar los $\delta \tilde{\omega} \rho \alpha$ que correspondan (Il.19.147), sin embargo, yace en la tienda Patroclo, y esto es motivo suficiente para decir: "Por eso nada de lo que dices me importa, sino la matanza, la sangre y el doloroso gemir de los hombres" (Il.19.213-4).

Según Finkelberg (1988), el abstenerse de pelear "no sólo no disminuye la timé de Aquiles, sino que de hecho la realza" (p.24), aunque esto tiene para Finkelberg un sentido negativo. Pues al negarse a luchar, al no actualizar su areté, Aquiles ha destruido su valor como guerrero y, de hecho, aquella areté ha dejado de existir. Homero estaría criticando los valores individualistas y aristocráticos, juzgándolos a partir de la ideología comunitaria de la polis del siglo VIII a.C. Así, habría una contraposición irreconciliable entre la idea de realizar una areté, como práctica emprendida por la emulación de los iguales, y la búsqueda de una timé que está dada por la cuna y la riqueza. Sin embargo, Aquiles actúa acá bajo la lógica de aquella timé contrapuesta incluso a la dada por Zeus a los reyes.

Vernant (2001) señala que a Aquiles, en su aplicación del código de honor, no le es lícito el más mínimo extravío. Él no puede ser medido con el mismo metro que a otros hombres y, por lo mismo, los dones ofrecidos por Agamenón nunca son suficientes. Él se muestra "insensible tanto a los ruegos y súplicas de sus amigos, como a las excusas y los intentos de reparación que deberían de satisfacerle" (p.48). Este extremismo con el que sigue el ideal y el honor heroico es lo que hace de Aquiles "un ser marginal, parapetado tras la altiva soledad de su indignación" (p.47) un singular completamente otro, respecto de reyes y vasallos. Y es que, para Aquiles no hay punto común entre la timé de la realeza, otorgada por Zeus, y aquella otra lograda en la primera línea de combate, en donde más acechan los peligros.

La hazaña heroica comporta una cualidad muy distinta a la de toda dignidad real, es más bien un momento de la existencia del hombre que levanta "esa condición humana que los dioses han querido mortal y sometida [...], tras la alegría juvenil, al declive de sus fuerzas y a la decrepitud" (p.56). La hazaña heroica pone la mismidad humana más allá del cerco de la muerte y la moira, 
hace de la carne del héroe poesía, hace de su porción ejemplo y espejo, una norma social contenida en el canto épico.

Un pasaje en que Aquiles aparece como un maestro de la moral que conlleva esta elevación del hombre por encima de su mortandad, es aquel en que Licaón debe aprender qué es un héroe. Allí Aquiles le dice "necio", "infantil"

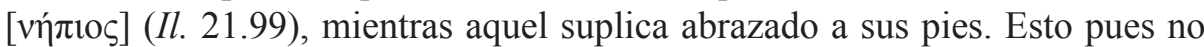
hay rescate alguno que pueda salvar a Licaón del destino. Y sin embargo,

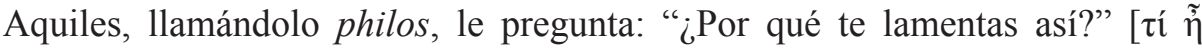

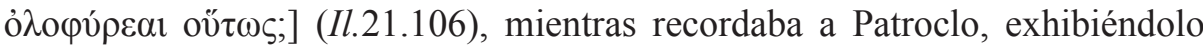

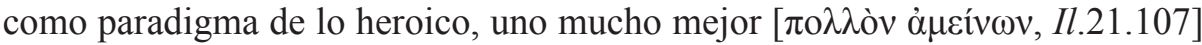
que este hombre que ahora llora por su vida. Pero Patroclo ha luchado y ha muerto. Aquiles le pide que mire a quién tiene ante sí, “¿No ves cómo soy

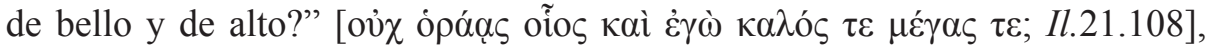
¿acaso no sabe Licaón del noble padre y la divina madre que han engendrado al héroe ante el que ahora llora? Sin embargo, a él mismo también lo aguarda la fatalidad al final del camino, pues, como Aquiles afirma:

Mas también sobre mí penden la muerte y el imperioso destino, y llegará la aurora, el crepúsculo o el mediodía en que alguien me arrebate la vida en la marcial pelea

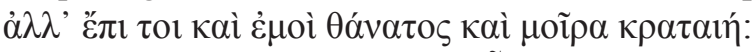

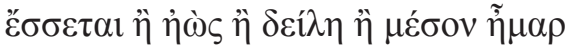

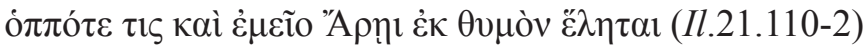

Sobre Aquiles también es la muerte y el poderoso destino. El corazón o la vida, en algún momento del tiempo, le será arrancado, tal vez, con las manos

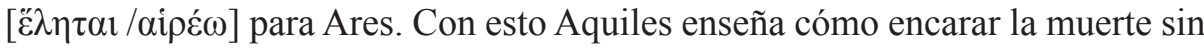
lamentos, exponiendo la manera en como él mismo vive su propia existencia en idénticos términos, incluso, amando y rodeándose de uno que, en su forma de morir y de buscar la muerte, se ubica en un mismo plano. Así, la mismidad de Aquiles se define por el modo en cómo él mismo se encara con la muerte, este es el método por el que la propia existencia se eleva hacia el ideal heroico, apropiándoselo para sí, realizándolo, siéndolo en mismidad.

Aquiles, no sólo expone a Licaón la naturaleza efímera del ser del hombre en general, sino que le enseña cómo existir. Vida y muerte se dan la mano en este pasaje y en la enseñanza de Aquiles. Morir adecuadamente, morir bajo el rigor y la decisión de la moral heroica exige una conducta vital, que se ha de sostener a lo largo de la propia existencia, por tanto, "morir" según la 
férrea norma del ideal heroico es "existir" según su contenido.

Pero no se debe pensar a Aquiles como un negador de la vida, comparando la idealidad encerrada en su existir con el de una vida trasmundana que sólo puede asegurar su mismidad por medio de una mirada despectiva hacia la vida y la realidad. Por el contrario, según Vernant, Aquiles

no puede aceptar hundirse, como cualquier hijo de vecino, en la oscuridad del olvido, acabando por fundirse con la indistinta masa de los «sin nombre». Desea habitar para siempre en el mundo de los vivos y vivir entre ellos, en ellos (p.87).

La tentativa de Aquiles es un acto de rebeldía frente a lo efímero de su propia existencia, la que ha de ser negada por aquella muerte de la diferencia respecto a todo otro, pérdida absoluta del sí mismo en lo caótico de una noche que infinitamente no logra aparecer bajo el aspecto de un uno determinado. El canto del aedo será la alternativa de Aquiles frente a esta oscuridad tan abismal, canto que hará de él una suerte de heterotopía. Para Foucault(1967), una heterotopía es un espacio otro que funciona en tanto institución social, en ella la sociedad se ve reflejada, contestada e invertida, a modo en cómo lo haría frente un espejo. Aquiles, al sellar su existencia asesinando a Héctor, empieza a existir como tal espejo contenido en el canto homérico.

Como decíamos antes citando a Vernant, Aquiles no puede contar con su cuerpo para convertirse en matador de la muerte, sino que ha de contar con la estela funeraria y sobre todo, con el canto poético, el que lo eleva de la condición mortal, desde su proporción, arrancándolo del anonimato y que lo convierte en uno de esos "«héroes ilustres» cuya figura, siempre presente en el espíritu de los vivos, refulge con un brillo que nadie puede debilitar: el brillo del kléosáphthiton, el de «la gloria imperecedera»" (p.32).

Este es el galardón y el valor supremo de la existencia, al cual sólo se accede por medio del rebelde enfrentamiento ante el cósmico límite de la muerte. De ahí, ante las palabras proféticas y últimas de Héctor, su certeza:

¡Muere! Mi parca yo la acogeré gustoso cuando Zeus quiera traérmela y también los demás dioses inmortales.

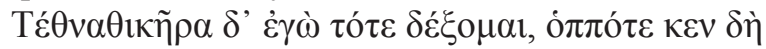

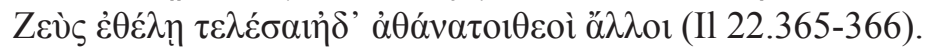




\section{Conclusión}

El esfuerzo emprendido en estas páginas pueda definirse como un intento por demostrar que el ser humano nunca es reducible a uno de sus elementos, por más sustancial quesea. Un pensamiento que ingrese en la naturaleza humana singular y existente, debe asumir el peso de verla como un fenómeno total, en el que sus momentos se estructuran vitalmente a partir de su mismidad.

Precisamente, Aquiles, paradigma del mundo aqueo, ha de ser visto a la luz del entrecruzamiento de los distintos momentos de, sí como un ser total, y no en un sentido inocente e idealista - negando su existencia inmediata, error inverso al que también se podría llegar por el camino totalmente opuesto de un positivismo obtuso que pretenda simplemente afirmar por sobre todo esta inmediatez. Las estructuras del ser de la mismidad homérica deben ser pensadas como desplegadas en su todo por la propia existencia, como un singular que se piensa y vive a sí mismo bajo aspectos tan diversos como lo son: sus entidades psicosomáticas, la superficie de su piel o la belleza de su rostro; pero también bajo aspectos que lo vinculan a una moral, sociedad, cosmos y destino. Cualquier intento de exponer la mismidad del ser humano que no dé cuenta de esta totalidad está condenado a una infinita repetición de una abstracción del ser orgánico total de esta mismidad.

\section{REFERENCIAS BIBLIOGRÁFICAS}

Homer. (1920). Homeri Opera in five volumes. Oxford, Oxford University Press. Homero (1991), Ilíada (trad. y notas de E. Crespo Güemes). Madrid, Gredos.

Chantraine, P. (1968). Dictionnaire étymologique de la langue grecque. Histoire des mots. Paris: Klincksieck.

Liddell, G., Scott, R., \& Jones, H. (1883).A Greek-English Lexicon. Oxford: Oxford Press.

Pavon de Urbina, José M. (2000). Diccionario manual griego: griego clásico-español. Barcelona: Vox.

AdKins, A. W. (1960). "Homer: Free Will and Compulsion". En Merit and Responsibility - A Study in Greek Values (pp. 10-29). Oxford: Oxford Universty Press.

Burkert, W. (2007). Religión griega. Arcaica y clásica. Madrid: Abada.

Clark, M. (1999). Flesh and Spirit in the Songs of Homer. Oxford: Claredon Press.

Dietrich, B. C. (1962). “THE SPINNING OF FATE IN HOMER”. En Phoenix, 16(2), 86-101.

Finkelberg, M. (1998). "Timē and Aretē in Homer". EnThe Classical Quarterly, 48, No.1, 14-28. 
Foucault, Michel. (1967) Des espacesautres (1967), Hétérotopies.

HeIdegger, M. (2005). Ser y Tiempo.Santiago: Editorial Universitaria.

Jowsey, N. (2011). The Meaning of Moira: Fate, Mesure and Glory in the Iliad (pp. 7-39). New York: A dissertation submitted to the Faculty of the Graduate School of the University at Buffalo, State University of New York in partial fulfillment of the requirements for the degree of Doctor of Philosophy.

Liu, C. (2010). The Motif of Fate in Homeric Epics and Oedipus Tyrannus. (pp. 11-45).

UC Riverside: Comparative Literature. Retrieved from: http:/escholarship. org/uc/item/9zz4x47x.

Long, A. (2015). Greeek Models of Mind and Self. Cambridge: Harvard University Press.

Martin, R., \& Barresi, J. (2006). The Tise and Fall of Soul and Self. An Intellectual History of Personal Identity. New York: Columbia University Press.

RoHDE, E. (1948). Psique: la idea del alma y la inmortalidad entre los griegos. Mexico: Fondo de Cultura Económica.

SNell, B. (1965). Las fuentes del pensamiento europeo. Estudio sobre el descubrimiento de los valores espirituales de occidente en la antigua Grecia.Madrid: Razón y Fe.

SorabJI, R. (2008). “Graeco-Roman Varieties of Self”. En P. -S. REMES (Ed.), Ancient Philosophy of the Self (pp. 13-34). Springer Science+Business Media B.V.

Sullivan, S. (1988). "APPROACHES TO HOMERIC PSYCHOLOGY". En Psychological Activity in Homer: a Study of Phrēn (pp. 1-19). Ottawa, Canada: Carleton University Press Inc.

Sullivan, S. (1994). "THE MIND AND HEART OF ZEUS IN HOMER AND THE HOMERIC HYMNS”. En Archiv Für Begriffsgeschichte, 37, 101-126.

Vernant, J.-P. (2001). El individuo, la muerte y el amor en la Antigua Grecia Barcelona: Paidós. 